\title{
The Perception of Lecturers on Public Speaking Anxiety among ESL Learners in a Public University (UITM)
}

Jebakumari Selvarani Ebenezer, Harwati Hashim, Nur Ehsan Bin Mohd Said To Link this Article: http://dx.doi.org/10.6007/IJARBSS/v12-i1/12204 DOI:10.6007/IJARBSS/v12-i1/12204

Received: 14 November 2021, Revised: 17 December 2021, Accepted: 30 December 2021

Published Online: 25 January 2022

In-Text Citation: (Ebenezer et al., 2022)

To Cite this Article: Ebenezer, J. S., Hashim, H., \& Said, N. E. B. M. (2022). The Perception of Lecturers on Public Speaking Anxiety among ESL Learners in a Public University (UITM). International Journal of Academic Research in Business and Social Sciences, 12(1), 1608-1620.

\section{Copyright: (c) 2022 The Author(s)}

Published by Human Resource Management Academic Research Society (www.hrmars.com)

This article is published under the Creative Commons Attribution (CC BY 4.0) license. Anyone may reproduce, distribute, translate and create derivative works of this article (for both commercial and non0-commercial purposes), subject to full attribution to the original publication and authors. The full terms of this license may be seen at: http://creativecommons.org/licences/by/4.0/legalcode

Vol. 12, No. 1, 2022, Pg. $1608-1620$

Full Terms \& Conditions of access and use can be found at http://hrmars.com/index.php/pages/detail/publication-ethics 


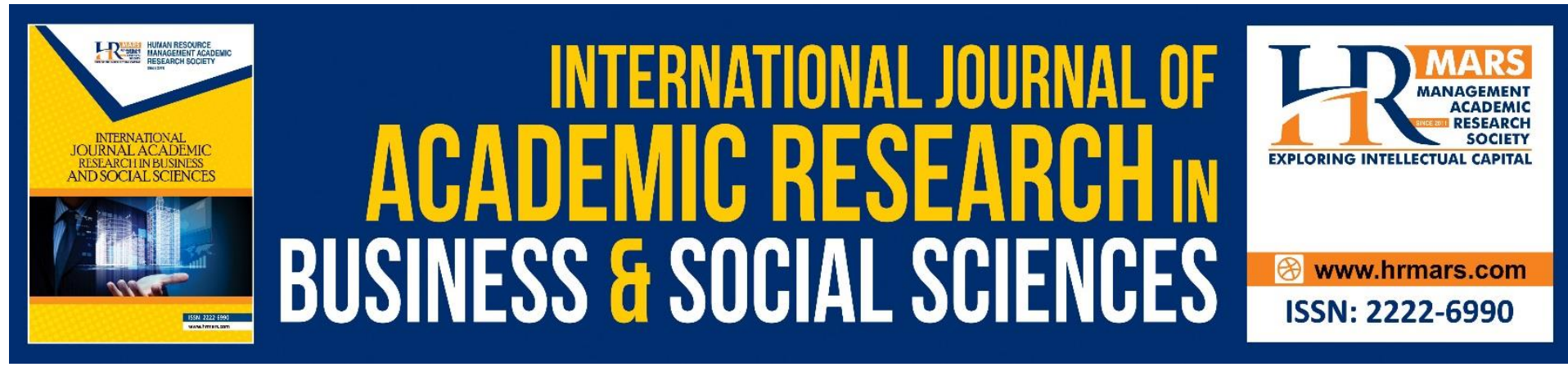

\title{
The Perception of Lecturers on Public Speaking Anxiety among ESL Learners in a Public University (UITM)
}

\author{
Jebakumari Selvarani Ebenezer (Corresponding Author), Dr. \\ Harwati Hashim, Dr. Nur Ehsan Bin Mohd Said
}

Akademi Pengajian Bahasa, Universiti Teknologi MARA Cawangan Selangor, Kampus Dengkil, Selangor, Malaysia, Fakulti Pendidikan, Universiti, Kembangan Malaysia, Bangi Selangor

\begin{abstract}
Numerous polls have been undertaken to recognise public speaking as a number one concern among undergraduates in University Technology Mara when involved in English courses. This is regardless of the fact the university offers ample opportunities for students to develop their public speaking skills. If public speaking is a struggle in the sense of a native English speaker, then the fear of enhancing sustainable oral presentations in English to non-native English speakers is understandably greater. Nevertheless, speaking in English in front of an audience is increasingly seen as a valuable ability for ESL/EFL learners to develop and that is why public speaking courses in many Malaysian university programs are increasingly seen as a key component. According to research conducted by the Ministry of Education as a result of internationalisation policies, public universities in Malaysia have switched to the English language as their medium of instruction. Public speaking is offered as a university prerequisite course in many of these universities, making it compulsory for many students. Students are apprehensive, however about public speaking in English. The present study explores publicspeaking apprehension in a public university among Malay learners of English. This study entailed a quantitative research paradigm on a sample of 30 lecturers who will interviewed using an interview pool. Data will be transcribed after the interview. This thesis aims to define techniques for the improvement of public speaking competences for adult ESL learners. Employees in the field at all various levels usually require good oral communication.
\end{abstract}

\section{Introduction}

In the proposed National Education Blueprint 2013-2025, learning the English language is an important element to ensure that Malaysia stays competitive both in the country and worldwide and has increased significantly in the recent years. A population that is fluent in the English language is important for this. In recent decades, a request to take courses based on instruction As a Second Language in English (ESL) has risen dramatically and is now deemed necessary to satisfy students' educational needs. Universities are at the forefront of ensuring that their learners can work successfully in the English language to fulfil these criteria. English is the main language of instruction in certain public universities and students are required to perform in English. They're going to need to write well and chat well. This is why universities 
give students different English language courses that help them develop their communication skills and resolve their fear of communication (Emanuel et al., 2008).

and learning of English.

Undergraduates need to be proficient and must be able to acquire public speaking and public speaking apprehension must not hinder them from performing well in their higher education accomplishments. The present study is based on the assumption that PSA is a real problem that affects students in higher learning institutions in Malaysia, with many suffering from various degrees of apprehension. Most Malaysian students would avoid any public speaking encounters all together, given a choice. They would try to "Reduce incidental interaction with other people and can prefer less visible seats in classes or meetings. " (McCroskey \& Beatty, 1998, p. 225).

In UiTM, ESL learners face a lot of difficulties in speaking and are very apprehensive when participating in public speaking. The scenario catalyzed further by the fact that English course attended by majority of the ESL students in general come from family backgrounds that speak Malay as their mother tongue. This research aims to provide a feasible method that enable these ESL students to achieve higher education and advancement in the workforce as an important applied skill for ESL learners via improved public speaking skills. While ESL course contents and instructions continues to concentrate on skill, ranging from reading, writing, grammar, listening to speaking; speaking abilities are still widely regarded as important applied capacity for new entry into the workplace. The process of teaching and learning English language has to be conveyed properly and thoroughly (Wu, 2010). Not only the comprehension and skills of the language are vital but also the courage and the assurance to speak up outside of their classroom settings and settings is required by an ESL learner. Jakelova (2012) stated in her study that those who have public speaking skills will be given a good job in comparison to those who are less capable. Therefore, with the public speaking learning opportunity that these learners have and the backup from the instructors and peers (Riedel, 2012; Kovac \& Sirkovic, 2012) could build-up learners' confidence level that is, the assurance to learn the language and later the build-up the self-assurance to apply the language in a written form and also verbally in public. Kovac \& Sirkovic (2012) also found out that ESL learners will become more conscious of the skills needed in oral presentation when the class comprises of peer evaluation to assess the speaker.

The aim of this research project is also to explore the anxiety experienced by UITM ESL learners in public speaking by getting feedback from thirty lecturers teaching this course. In public speaking presentations, the anxiety level will be tested. It will also discuss in-class approaches used by lecturers to handle public-speaking apprehension and methods used by lectures at University Technology Mara to improve their public-speaking skills. The researchers will also define different techniques to assist adult ESL learners to improve their public speaking skills. For most learners, apprehension or anxiety are normal in public speaking.

Public speaking anxiety has also been referred to as: speech anxiety, stage fright, public speaking anxiety and public speaking fear (Ayres \& Hopf, 1993, p. 4). Ayres and Hopf (1993, p.4) defined speech anxiety as "those situations when an individual reports he or she is afraid to deliver a speech". They further explained what PSA is not-"situations in which a person experiences anxiety but is not aware of the source of the anxiety" (p. 4). When speaking or 
writing, they typically make use of unique language patterns or regularities. Since nervous people have less faith in their thoughts and decisions, they are likely to initiate contact in order to reassure other people or manipulate them.

Several studies have shown that this widespread phenomenon relates to contact apprehension. Nevertheless, studies that discuss the impact of apprehension on communication behaviour and efficacy are somehow incomplete and are based on expression. It can be observed through speech as well as written communication via analogy and observation. The theory of contact apprehension notes that highly-apprehensive people (McCroskey \& Richmond, 1990: Scott \& Timberland, 2005). Research shows that because of prior conditioning, communication apprehension can occur. He discovered that public speaking was a mandatory class for all students when McCroskey became the chair of the communication department.

West Virginia University in 1972. This was a smart step to help transform students to mature in their academic ability in public speaking. As an UiTM lecturer, after engaging in public speaking, the researcher has seen his own students becoming brave and confident.

McCroskey (2007) reflected about this change, stating "the enrolments in the department tripled in four years. Clearly, public speaking classes are very beneficial to most students, those that are not high communication apprehension. Requiring public speaking classes for high CAs may do as much harm, or even more, than they benefit these students" (p. 183).

It has been shown to be very normal to avoid speaking in public. Those fears take one of five types, according to Wilder (1999): I work terror, ii) perfectionism, iii) panic, iv) avoidance, and v) trauma. Wilder defines the five fears as follows: career terror is "rooted in the awful feeling that your job, your career, your future is on the line every time you step before a group, enter a meeting, or pick up the telephone". The speaker is paralysed by perfectionism as they demand that each speech or presentation be flawless. Panic is the mixture of unrealistic expectations and actual physical symptoms with fear of failure. Avoidance "is a self-sabotage that almost guarantees anxiety, anxiety, and reduced performance." Trauma is insecurity that has been rooted in a long history of being told that you are not good enough. The fear of being judged by an audience involves feelings of inadequacy or an odd accent with regard to dress style. By accepting the fact that three-quarters of the audience share this fear, it is mitigated. A fear of being in the spotlight is performance anxiety or stage fright. These emotions are used by experienced public speakers to get an adrenaline rush, which gives an additional boost of motivation to engage the audience. During a speech, inexperienced public speakers frequently fear losing their audience.

Fear of failure affects public speakers who during the speech, become scared that they will come across as boring. Entertainment practitioners recognise that viewers root for speakers to excel and prevent the causes of humiliation failure. The report, though leaving considerable space for further research into the effects of PSA, indicates that, relative to low PSA students, anxiety does not significantly affect the academic learning of high PSA individuals. Although it is reasonable to conclude that a disproportionate number of highly anxious students would result in speech performance courses needed for all students as part of a general education curriculum, it does not follow that teacher would recognise the impact of PSA on the learning of the content of the course. This study therefore shows that lecturers of oral presentation 
courses where registration is required should be more concerned with the effects of PSA on oral performance than with content learning.

\section{Research Objective}

Identifying the perceptions of lecturers on factors that causes public speaking anxiety among ESL Learners during public speaking presentations.

\section{Research Question}

What are the factors of the anxiety level experienced by young adult ESL learners in public speaking presentations?

\section{Literature Review}

Many researches have been carried out to examine the factors that bring about anxiety while speaking. Researchers have acknowledged several causes that are held responsible for speaking anxiety. Many factors such as linguistic, psychological, physiological and cultural factors affect and cause second language speaking anxiety. The learners' explanation may be affected due to situation- specific-reasons or performance conditions. According to Horwitz (2001), during L1 and L2 learning process, comprehension apprehension (CA) can affect learners. It is specifically linked to how language is used. Other than the student-linked causes, many other external sources take part in language anxiety, i.e., lack of proper backup from teachers, learners' unresponsive character and individual care. (Day \& Gu, 2013; Siyli \& Kafes, 2015). Ellis (2015) stressed out that due to shortage of linguistic knowledge the learner's anxiety level might go high. In 2013, Kayaoglu and Saglamel's interview session with 30 Turkish EFL students showed that language matters faced by the learners' (word power, grammatical and pronunciation difficulties) increased the level of language anxiety. The anxiety level of the students surges due to various reasons such as not interesting activities, short of collaboration, inappropriate teaching style, highly demanding and conditioned classroom ambience, time management reasons, and irrelevant content of teaching (Zia \& Norrihan, 2015). McCroskey (2015) described that lack of self-assurance in an individual's skill and unwillingness to be involved in communication or interaction are inter-connected as it is due to be afraid of peer evaluation.

\section{Findings Interpretations and Discussions}

The research, which improved the entire results of this report, will be addressed explicitly in this chapter. Via their practise, ESL learners during public speaking presentations will highlight the level of anxiety in the study. Respondents from four chosen UiTM units, primarily Engineering, Applied Technology, Art and Design and Sport Science, were presented with the findings of the well-prepared questionnaire.

Public-speaking anxiety, also referred to as public-speaking anxiety or stage panic, involves a core fear of being observed or judged by others, this fear is typically followed by a number of physical and emotional responses that may greatly interfere with the speech or presentation of a person, including inability to deliver a speech or presentation effectively, including extreme speech or presentation. Nervousness, sweating and/or dizziness, trembling or shaking.

When asked to perform a public speaking presentation, the respondents who Adult Malay ESL learners mainly from all faculties experience high degree of anxiety. Most Malay adult ESL learners demonstrate that when engaged in a public speaking situation where they are unable 
to effectively complete a public speaking presentation due to fear, the extent of anxiety is an obstacle to them.

\section{Data Analysis}

\section{Survey Reliability}

A requirement for legitimacy is durability. Reliability is synonymous with reliability, accuracy and replicability over time, over tools and groups of participants. (Cohen, Manion \& Morrison, 2007). In order for a sample to be accurate, it must prove that it must be performed in a similar group of respondents in a similar setting, and then comparable findings can be observed. In this analysis, Cronbach's Alpha (1951) was determined using the social sciences service (SPSS) programme after the items of the various variables were chosen. The average reliability was computed as 0.808 for the current analysis. In general, the reliability of research papers with values greater than 0.80 indicates very high reliability for research purposes. (Hair et al., 1998)

The results based on the questionnaires presented demonstrate that by measuring the measurement skewness and kurtosis for each item, the normality for any item in the measurement model. The absolute skewness value of 1.0 or below means that the data is usually distributed and that the spectrum is between -0.5 and 0.5 . This analysis concludes that the data is symmetrical or bell-shaped. The bel shape indicates the regular distribution of the results. The data collected in the thesis therefore follows the necessary assumptions that data comes from normal distribution for the use of parametric statistical analysis. In order to illustrate a normal univariate distribution, asymmetry and kurtosis values between -2 and = 2 are considered appropriate (George \& Mallery, 2010).

\section{Value of KMO}

\section{Table 3: Value of KMO and Bartlett's test of sphericity}

The result in Table 3 shows that KMO value for all construct is 0.852 which fall in the range good, so this study be confident that the sample is adequate to proceed into Factor Analysis and the Bartlett's Test of Sphericity was significant for all construct since p-value $<0.001$. Hence th

\begin{tabular}{|c|c|c|}
\hline \multicolumn{3}{|l|}{ KMO and Bartlett's Test } \\
\hline \multicolumn{2}{|c|}{ Kaiser-Meyer-Olkin Measure of Sampling Adequacy. } & \\
\hline \multirow{3}{*}{ Bartlett's Test of Sphericity } & Approx. Chi-Square & $\begin{array}{l}.852 \\
2451.550\end{array}$ \\
\hline & df & 528 \\
\hline & Sig. & .000 \\
\hline
\end{tabular}

For the 33 objects, the principal component Factor Analysis (PCA) with varimax rotation was conducted. The comparison of the KMO and Bartlett shows that the importance of the KMO is for both. Build is 0.852 , which lies right in the range, so this research is optimistic that the sample is appropriate to progress to Factor Analysis and the. Since p-value,0.001, Bartlett's sphericity test was important for all constructs. Thus the data is sufficient to continue with the reduction process. 


\section{Test Sample Adequacy}

The Kaiser-Meyer-Olkin is the sampling adequacy measure, which ranges from 0 to 1 . Values similar to 1 are higher, and the minimum value suggested is 0.6 . An observed correlation matrix is compared to the identity matrix by the Bartlett's Test of Sphericity. Essentially, it scans to see if there is some duplication that we can sum up with a few variables between the variables. The test's null hypothesis $(\mathrm{HO})$ is that the variables are orthogonal, meaning not correlated. The alternative hypothesis $(\mathrm{H} 1)$ is that the variables are not orthogonal, implying that they are heavily correlated where the matrix of correlation varies greatly from the matrix of identity. This test is usually conducted before we implement a data reduction technique to check that a data reduction technique may potentially compact the data in a more realistic manner, such as main component analysis or factor analysis. Taking this into account, these tests set the minimum prerequisite for Factor Analysis to continue.

\section{Test Hypothesis Regarding Interrelationship between the Variables}

Null Hypothesis $\mathrm{HO}$ : There is no statistically significant interrelationship between variables affecting the anxiety level of young adult Malay (ESL) learners during public speaking presentation.

Alternate Hypothesis $\mathrm{H} 1$ : There may be a statistically significant interrelationship between variables affecting the anxiety level of young adult Malay (ESL) learners during public speaking presentation

Table 3: Value of KMO and Bartlett's test of sphericity

\section{KMO and Bartlett's Test}

\begin{tabular}{|lc|l|l|}
\hline $\begin{array}{l}\text { Kaiser-Meyer-Olkin } \\
\text { Adequacy. }\end{array}$ & Measure of Sampling & .852 \\
Bartlett's Test & of Approx. Chi-Square & 2451.550 \\
Sphericity & Df & 528 \\
& Sig. & .000 \\
\hline
\end{tabular}

The result in Table 3 shows that KMO value is 0.852 which indicates that the sample is adequate and we may proceed with the Factor Analysis. Taking a 95\% level of significance ( $\alpha=0.05$ ), the $p$-value (Sig.) of $.000<0.05$, therefore the Factor Analysis is valid. As $p<\alpha$, we therefore reject the null hypothesis $\mathrm{HO}$ and accept the alternative hypothesis $(\mathrm{H} 1)$ that there may be statistically significant interrelationship between variable.

The sampling adequacy measure of Kaiser-Meyer Olkin (KMO) and Bartlett's Test was used to analyze the appropriateness of the Factor Analysis. The approximate of Chi-square is 2451.550 with 528 degrees of freedom, which is significant at 0.05 level of significance. The $\mathrm{KMO}$ statitic of 0.852 is also large and greater than 0.60 . Hence, Factor Analysis is considered as an appropriate technique for further analysis of the data. 


\subsection{Factor Analysis}

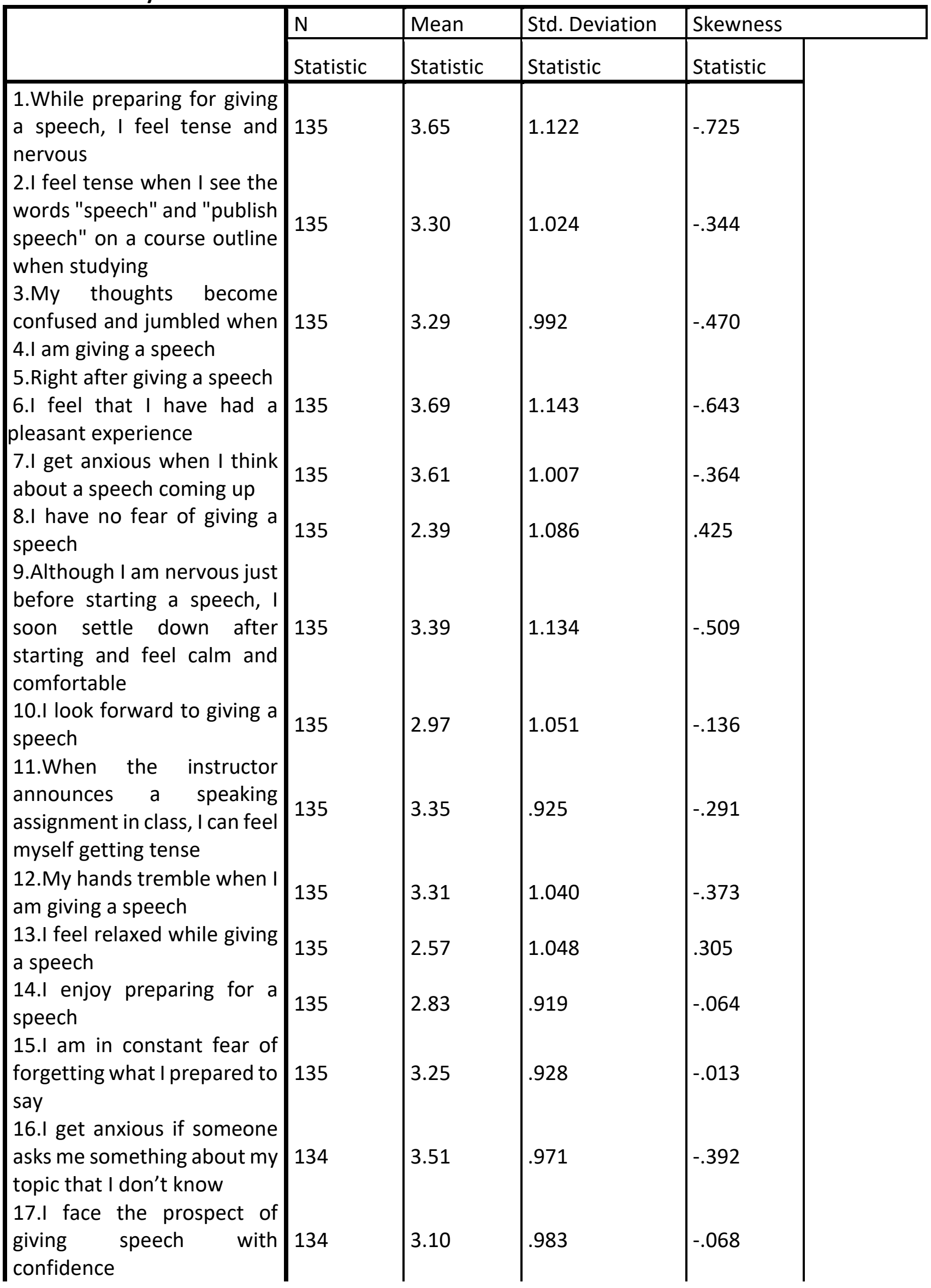


18.I feel that 1 am in complete possession of 135 myself while giving a speech 19.My mind is clear when giving a speech

20.1 do not dread giving a speech

21.I perspire just before starting a speech

22. My hearts beats very fast just as I start a speech

23.I experience considerable anxiety while sitting in the room just before my speech starts

24.Certain parts of my body feel very tense and rigid while giving a speech

25. Realizing that only a little time remains in a speech makes me very tense and anxious

26. While giving a speech, I know I can control my feelings of tension and stress 27.I breathe faster just before starting a speech

28.I feel comfortable and relaxed in the hour or so just before giving a speech 29.I do poorer on speechless because I am anxious

30.I feel anxious when the teacher announces the date of a speaking assignment 31. When I make a mistake while giving a speech, I find it hard to concentrate on the parts that follow

32During an important speech I experience a feeling of helplessness building up 135 2.83

3.05

.957 $-.260$ inside me

33.I have trouble falling asleep the night before a 


\begin{tabular}{|l|l|l|l|l|}
$\begin{array}{l}\text { 34.My heart beats very fast } \\
\text { while I present a speech }\end{array}$ & 135 & 3.40 & 1.080 & -.278 \\
$\begin{array}{l}35 . \text { feel anxious while } \\
\text { waiting to give my speech } \\
\text { Valid N (listwise) }\end{array}$ & 135 & 3.64 & 1.012 & -.491 \\
\hline
\end{tabular}

For the PRSPSA survey results, besides computing for the total anxiety scores: factor analysis was also accomplished to determine the underlying data concepts of the data gathered. Factor Analysis is a method of grouping together variables (or items) which have something in common. It's a process that enables the researcher to take a set a variable and reduce them to

smaller number of underlying factors which account for as many variables as possible (Cohener.al.,2007). Factor analysis actually detects structure sand commonalities in the relationship between variables.

Therefore, factor analysis enables researchers to identify where different variables are in fact addressing the same underlying concepts. Results obtained in Appendix 1 shows the factor loading for all 33 items fall under 8 components. The study will select the items using the above criteria to be grouped under the respective components, component 1,2,3,4,5,6,7 and 8. Stevens (1992) recommends interpreting only factor loadings with an absolute value greater than 0.4 (which explain around $16 \%$ of variance). In this case, item $19,20,21,22,23,25,27,28,29,30$ and 33 falls under component 1, item 1,2,3,5 and 31 under component 2 , item 9,13,14 under components 3 , item 6,8,11,12, and 17 under component 4, item 7,15,16 and 24 under component 5, item 10 and 32 under component 6, item 18 and 26 under component 7 and item 4 under component 8.

Based on the pattern matrix in Appendix 2 this study observed 8 patterns. The patterns was classified under 8 factors which are as follows:

$\begin{array}{rrrrr}\text { Factor } & 1 & : & \text { Feeling } & \text { Anxious. } \\ \text { Factor } & 2 & : & \text { Feeling } & \text { Nervous } \\ \text { Factor } & 3 & : & \text { Feeling } & \text { Fearful } \\ \text { Factor } & 4 & : & \text { Feeling } & \text { Confident } \\ \text { Factor } & 5 & : & \text { Feeling } & \text { Calm }\end{array}$

Factor 6 : Physical Consequence of Public Speaking Apprehension Factor 7 : Positive Attitude towards Public Speaking Apprehension Factors 8 : Pleasant Experience after Public Speaking

\section{Factor 1: Feeling Anxious}

19. I perspire just before starting a speech

20 My hearts beats very fast just as I start a speech

21I experience considerable anxiety while sitting in the room just before my speech starts

22 Certain parts of my body feel very tense and rigid while giving a speech

23 Realizing that only a little time remains in a speech makes me very tense and anxious

25 I breathe faster just before starting a speech

70

27 I do poorer on speechless because I am anxious

28I feel anxious when the teacher announces the date of a speaking assignment

29 When I make a mistake while giving a speech, I find it hard to concentrate on the parts that follow

30 During an important speech I experience a feeling of helplessness building up inside me 


\section{3 | feel anxious while waiting to give my speech}

\section{Factor 2 Feeling Nervous}

1 While preparing for giving a speech, I feel tense and nervous

2 I feel tense when I see the words "speech" and "public speech" on a course outline when 2 studying

3 My thoughts become confused and jumbled when I am giving a speech

5 I get anxious when I think about a speech coming up

31 I have trouble falling asleep the night before a speech

Factor 4: Feeling Confident

6 I feel that I have had a pleasant experience

8 I have no fear of giving a speech

${ }_{11}$ When the instructor announces a speaking assignment in class, I can feel myself getting 11

12 My hands tremble when I am giving a speech

7 I face the prospect of giving speech with confidence

Factor 3: Feeling Fearful

Factor 5 Feeling Confident

9 Although I am nervous just before starting a speech, I soon settle down after starting and 9 feel calm and comfortable

Although I am nervous just before starting a speech, I soon settle down after starting and 13 feel calm and comfortable

14| enjoy preparing for a speech

7 Although I am nervous just before starting a speech, I soon settle down after starting and feel calm and comfortable

15 I face the prospect of giving speech with confidence

16 I feel that I am in complete possession of myself while giving a speech

24 While giving a speech, I know I can control my feelings of tension and stress

Factor 6: Physical Consequence of Public Speaking Apprehension

Factor 7 Positive Attitude towards Public Speaking Apprehension

Factor 8: Pleasant Experience After Public Speaking

\begin{tabular}{|l|l}
\hline 4 & Right after giving a speech, I feel that I have had a pleasant experience \\
\hline
\end{tabular}

Reliability Statistics

\begin{tabular}{|l|l|l|}
\hline & $\begin{array}{l}\text { Cronbach's } \\
\text { Alpha Based } \\
\text { on } \\
\text { Standardized } \\
\text { Items }\end{array}$ & \\
Alpha & .898 & N of Items \\
\hline .898 & 33 \\
\hline
\end{tabular}

The Cronbach's alpha of the overall item [Personal Report of Public Speaking Anxiety (PRPSA)] scale is 0.898 when the scores of all 33 -items are combined. 
Table $^{* *}$ : Reliability statistics for measuring variables

\begin{tabular}{|l|l|l|}
\hline Factor & Cronbach's Alpha & No of Item \\
\hline 1 & 0.908 & 11 \\
\hline 2 & 0.855 & 5 \\
\hline 3 & 0.775 & 3 \\
\hline 4 & 0.752 & 5 \\
\hline 5 & 0.760 & 4 \\
\hline 6 & 0.753 & 2 \\
\hline 7 & 0.502 & 2 \\
\hline
\end{tabular}

Table $^{* *}$ above shows the value of cronbach alpha for measuring item in the variable.

Factor 1 consist of 11 items with cronbach alpha equal to 0.908 followed by factor 2 which consist of 5 items with cronbach alpha equal to 0.855 . While Factor 3 consists of 3 items, factor 4 have 5 items, factor 5 have 4 items, factor 6 have 2 items with each cronbach alpha equal to $0.775,0.752,0.760$ and 0.753 respectively. Only factor 7 have low value of cronbach alpha with 0.502 . Factor $1,2,3,4,5$ and 6 are reliable to proceed since cronbach alpha are greater than 0.6. Factor one to factor 6 have values than are greater than 0.6 for cronbach alpha. Only factor 7 has 0.502 Cronbach value which is less than 0.6. Therefore Factor 1 to factor 6 are reliable to proceed. When two of the items are deleted (Factor 7), the overall cronbach alpha is increased to 0.901 .

\section{Conclusion and Recommendation}

To summarize, findings suggests that there are a lot of different factors that could cause anxiety, such as feeling anxious, feeling fearful, feeling nervous and many others. In reality, even though female students have more TPS, they experience more PSA than their male student counterparts, and this is primarily because they (female students) are more conscious with their grades. However, in a general sense, PSA is quite normal, it happens to most of us. In the good side, the yearlong public speaking course program has positively contributed to the overall students' English speech proficiency. This study is only limited to the students of the four faculties in Uitm mainly Engineering, Applied Science, Art and Design and Sport Science. In addition, factors such as students' personality, self-perceptions, beliefs, attitudes, intelligence, teaching style, classroom and campus climate, and many others should be included in the assessment of the various causes and implications of PSA.

This research is significant and beneficial to lecturers because it sheds light on the factors that contribute to learners' anxiety. Additionally, it serves as a starting point for identifying the causes of language anxiety and developing strategies to assist learners in overcoming their stress. The findings are applicable not only to students and lecturers, but also to others who are experiencing language anxiety such asschool and colleges.

\section{References}

Ayres, J., \& Hopf. (1993). Coping with speech anxiety. Norwood, N.J: Ablex Pub. Corp. Chicago, 15th edcountid 42518.

Day, C., and Gu, Q. (2013) "Resilient teachers, resilient schools: Building and sustaining quality in testing times", Routledge, New York.

Ellis, R. (2015) “Understanding Second Language Acquisition”, Oxford University Press, Oxford.

Hair, J. F. J., Anderson, R. E., Tatham, R. L., Black, W. C. (1998). Exploratory and confirmatory 
and confirmatory factor analysis of the per or analysis of the perceived switching ed switching costs model in the business services sector.

Horwitz, E. K. (2001). Language anxiety and achievement. In: Annual Review of Applied Linguistics, vol. 21, pp. 112-126. ISSN 0267-1905.

Horwitz, E. K. (2001) "Language Anxiety and Achievement", Annual Review of Applied Linguistics 21, 112-26. http://search.proquest.com.ezaccess.library.uitm.edu.my /docview/1027548730?ac

Jokelova, A. (2012). Effects of relevance- and confidence-enhancing motivational strategies, suggested strategies, and statements on academic performance and course satisfaction in undergraduate students of a blended public speaking course. (Order No. 3546504, University of South Alabama). ProQuest Dissertations and Theses, , 201.Retrievedfromhttp://search.proquest.com.ezaccess.library.uitm.edu.my/docview /1266831892? accountid 42518. (1266831892). Journal of English and Education, 4(1), 239-249

Kayaoğlu, M. N., and Sağlamel, H. (2013) "Students' perceptions of language anxiety in speaking classes", Journal of History Culture and

Kayaoğlu, M. N., and Sağlamel, H. (2013) "Students' perceptions of language anxiety in speaking classes", Journal of History Culture and

Kayaoğlu, M. N., and Sağlamel, H. (2013) "Students' perceptions of language anxiety in speaking classes", Journal of History Culture and

Kayaoğlu, M. N., and Sağlamel, H. (2013) "Students' perceptions of language anxiety in speaking classes", Journal of History Culture and

Kayaoğlu, M. N., and Sağlamel, H. (2013) "Students' perceptions of language anxiety in speaking classes", Journal of History Culture and Art Research, 2(2), 142-160.

Kovac, M. M., \& Sirkovic, N. (2012). Peer evaluation of oral presentations in Engage Students with Public Speaking Apprehensions.

McCroskey, J. C. (2007). Communication apprehension: What have we learned in the last four decades. Human Communication, 12(2): 179-187.

McCroskey, J. C. (2015). Introduction to rhetorical communication (9 $9^{\text {th }}$ Edition). New York, NY:Routledge

McCroskey, J. C., \& Richmond, V. P. (1990). Willingness to communicate: A cognitive view. Journal of Social Behavior \& Personality, 5(2): 19-37.

Riedel, D. (2012). A narrative inquiry exploring how college communication professors engage students with public speaking apprehension. (Order No. 3529201, University of the Incarnate Word). ProQuest Dissertations and Theses, 140. Retrieved from http://search.proquest.com.ezaccess.library.uitm.edu.my/docview/1095702384? Accounted 42518. (1095702384).

Wilder, L. (1999). 7 Steps to Fearless Speaking. John Wiley \& Sons.

Wu, K. H. (2010). The Relationship between Language Learners' Anxiety and Learning

Zia, Z., \& Norrihan, S. (2015). EFL learners' levels of classroom perform anxieties and their causes in classroom speaking activities in Afghanistan International Journal of English and Education, 4(1),239-249. 